\title{
Perioperative Optimization of Patients Undergoing Bariatric Surgery
}

\author{
C. E. Owers, ${ }^{1}$ Y. Abbas, ${ }^{1}$ R. Ackroyd, ${ }^{1}$ N. Barron, ${ }^{2}$ and M. Khan $^{1}$ \\ ${ }^{1}$ Department of Upper GI Surgery, Sheffield Teaching Hospitals, South Yorkshire, Sheffield S5 7AU, UK \\ ${ }^{2}$ Department of Anaesthesia, Sheffield Teaching Hospitals, South Yorkshire, Sheffield S10 2JF, UK
}

Correspondence should be addressed to C. E. Owers, corinneowers@doctors.org.uk

Received 28 November 2011; Accepted 5 June 2012

Academic Editor: Natan Zundel

Copyright ( $) 2012$ C. E. Owers et al. This is an open access article distributed under the Creative Commons Attribution License, which permits unrestricted use, distribution, and reproduction in any medium, provided the original work is properly cited.

\begin{abstract}
Bariatric surgery is fast becoming an efficient and safe method of weight reduction, especially for patients in whom conservative measures have failed. As the obese population of the world increases, so will the number of patients requesting or requiring surgical weight loss methods. Bariatric patients however have numerous co-morbidities that make their operative course more difficult, and therefore is important to have a good understanding of the important issues surrounding their pre, peri and post operative management. This article aims to educate the reader about optimal management of the bariatric surgical patient.
\end{abstract}

\section{Introduction}

As the number of bariatric patients increases and surgical procedures become safer and more efficient, the number of patients considering bariatric surgery is likely to continue to climb. The latest UK survey conducted by the Department of Health in 2009 showed that $61.3 \%$ of adults (aged 16 or over), and $28.3 \%$ of children (aged 2-10) in England were overweight or obese [1]. A further report, known as "The foresight report" issued in 2007 predicts that if no action was taken, $60 \%$ of men, $50 \%$ of women, and $25 \%$ of children would be obese by 2050. Current UK guidelines recommend bariatric surgery be offered to patients who have a BMI (body mass index) of $>40 \mathrm{~kg} / \mathrm{m}^{2}$, or $>35 \mathrm{~kg} / \mathrm{m}^{2}$ with a significant obesity-related comorbidity such as diabetes or hypertension, although delivery of this varies significantly.

Conservative approaches to managing obesity such as dieting, exercise, and cognitive behavioural therapy produce significant durable weight loss in only a minority of highly motivated patients. Drugs such as orlistat lead only to modest weight loss of approximately $4-8 \mathrm{~kg}[2,3]$ and can have unpleasant side effects such as steatorrhoea and diarrhoea, making compliance with medication as an issue. In patients where these lifestyle modifications have failed, surgery may be a valid option. However, bariatric surgery is not without a significant risk.

\section{Preoperative Optimisation}

It is important that when evaluating patients for bariatric surgery, they are managed by the multidisciplinary team because of the complexity of both their physiological state, but their psychological health too [4]. This may include a number of health professionals including diabetologists, specialist nurses, specialist dieticians, and psychologists as well as the surgeons and anaesthetists.

Bariatric operations, like many types of elective surgery, carry mortality risks, and although mortality risks are decreasing with routine postoperative high-dependent care and improving technologies, the obese population should be considered a high mortality risk. Therefore, bariatric surgery should only be performed in high-volume specialist centres. The UK's First National Bariatric Surgery Registry published data from 2009-2010 — only 7 postoperative deaths were recorded from a total of 7, 045 operations. There were no deaths from gastric banding or sleeve, and rouxen-y gastric bypass showed mortality risk of $0.2 \%$, which compares favourably with the best internationally published data.

Bariatric patients have a high number of cardiovascular and respiratory co-morbidities associated with their high BMI. Before considering surgery, it is important to assess the significance of these associated pathologies as this will 
affect not only the type of surgery offered, but will have a significant impact on the anaesthetic and their recovery. Although worldwide consensus as to the best operations for minimizing comorbidities differs, many operations have been shown to contribute to significant reduction of obesityrelated diseases.

Significant co-morbidities include type II diabetes, hypertension and stroke [5], hyperlipidemia [6], heart failure [7], atrial fibrillation/flutter [8,9] venous thrombosis [10], and obstructive sleep apnoea [11-17]. In many cases, weight loss of approximately 5-10\% can be associated with marked reductions in the risk of these chronic diseases [18]. A report issued by the Diabetes Prevention Program showed that a weight loss of about 5-6\% among persons with a BMI of $34 \mathrm{~kg} / \mathrm{m}^{2}$, along with increased physical activity, resulted in a $58 \%$ reduction in the incidence of diabetes [19]. When considering the type of operation best for people with type 2 diabetes, consideration must be given to the restrictive or malabsorptive components of surgery. The biliopancreatic diversion and duodenal switch have been shown to improve glycaemic control in up to $100 \%$ of patients $[20,21]$, but these operations are associated with significant malnutrition. The gastric band has a more modest type 2 diabetes remission rate (50-56\%) [22], gastric sleeve 50-90\% [23, 24], and roux-en-y gastric bypass has been shown to have an average remission rate of $83 \%$. Therefore when selecting an operation, clinicians should be aware of the patient's hypoglycaemic control.

All patients should be encouraged to lose weight before their surgery [25]. Small amounts of weight loss result in substantial reductions in visceral fat with a marked improvement in the ease of any subsequent bariatric procedure. Preoperative weight loss also establishes a patient's ability to comply with postoperative dietary regimens and may serve as a predictor for long-term success for the operation [26].

Morbidly obese patients are at high risk for developing DVT postoperatively following any operation-this has been shown to be as high as 2.5 times the risk as in a patient of healthy weight [27]. This can be attributed partly to the limited ambulation of obese patients, but also because of the inflammatory component of obesity [28, 29]. A rare but serious occurrence is pulmonary embolism, occurring in approximately $1 \%$ to $2 \%$ of cases [30], but which carries a $20 \%$ to $30 \%$ mortality [31]. Although no consensus exists on the practice prescribing pre- and post-operative subcutaneous anticoagulation, in many centres this is considered a routine practice. Some surgeons recommend preoperative lower extremity duplex testing for the presence of established DVT before performing bariatric operations. When found, an inferior vena cava filter can be placed to minimize the risk of postoperative pulmonary embolism [26]. The UK's National Bariatric Surgery Registry Report demonstrated that in 2009-2010, 4 patients had a documented postoperative pulmonary embolus, and there were 3 recorded DVTs.

Hypertension is one of the most common co-morbidities associated with obesity with approximately $40-70 \%$ of bariatric patients needing treatment $[32,33]$. Mechanisms proposed to explain the contribution of obesity to the development of hypertension include an altered reninangiotensin-aldosterone system, increased intra-abdominal pressure [34], increased sympathetic nervous system activity, development of insulin resistance, hyperleptinemia, leptin resistance, altered coagulation factors, as well as inflammation and endothelial dysfunction $[33,35]$. Patients, in conjunction with their primary care physician, should aim to have their hypertension well controlled before undergoing any surgical procedure, especially bariatric surgery. Many patients who suffer from hypertension will have an element of cardiac failure. The combination of increased adipose cells and increased lean muscle mass in obese patients results in high cardiac output and an increased circulating volume, also contributing to hypertension. Weight loss caused by caloric restriction or surgery promotes favorable hemodynamic changes referred to as reverse remodeling. Regression of left ventricle (LV) mass and chamber size after weight loss has been shown universally. Some evidence suggests that the greatest regression of LV mass and hypertrophy may occur when weight loss is combined with beta-adrenergic blocker therapy [36]. Opinions must be sought from a specialist if the cardiac history is complex. Patients often have a poor exercise tolerance often due to arthritis and general poor mobility rather than cardiovascular disease, although any evidence of heart failure should warrant a transthoracic echo (TTE). Due to the amount of adipose tissue, poor views are most often found during this test. Transoesophageal echo (TOE) is a better investigation, but is not universally available.

Obstructive sleep apnea (OSA) has a prevalence of $77 \%$ among obese patients [37] - a neck circumference of more than 17 inches in men and 16 inches in women is a good predictor of OSA [38]. Since the majority of obese patients prior to bariatric surgery will exceed these measurements, routine polysomnography testing for all patients prior to surgery is recommended [37]. Most anaesthetists require OSA patients to use a CPAP (continuous positive airway pressure) machine for a time before the operation, although there is no consensus about the length of time in which this should be used. Patients with more complex sleep disorders such as obesity hypoventilation syndrome will need post-op BIPAP and are at a higher risk.

Optimisation of many of the known risk factors must include early implementation of an attitude of healthy lifestyle in the months prior to surgery. This encourages patients to adopt health promoting behaviours early on, which can be continued postoperatively increasing the success of the operation. Advice regarding regular physical exercise for 30 minutes a day will aid cardiac function as well as insulin control. Dietary advice regarding low fat, low salt, and high vegetable diets will decrease atherosclerosis in the long term (although unlikely to impact in the months prior to surgery), as will cessation of all smoking. In many centres, patients attend seminars preoperatively that have a strong input from a specialist bariatric dietician, who can advise on pre- and post-operative nutrition.

A higher prevalence of nutritional deficiencies was found amongst people with morbid obesity. Nutritional assessment is, therefore, a key prior to surgery to minimize postoperative complications [39]. The most prevalent deficiencies were 
iron, ferritin, folic acid, and the presence of anemia, with high PTH levels reflecting low levels of vitamin D [40, 41].

Steatohepatitis frequently accompanies morbid obesity and can cause hepatomegaly; $33 \%$ of morbidly obese patients show fatty infiltration in more than $50 \%$ of hepatocytes [42]. This may result in difficulty viewing as well as risk of severe bleeding during laparoscopic surgery. The use of a 2-week VLCD (very low-calorie diet) preoperatively has been shown to cause significant weight loss if the patient complies with the liquid diet. Furthermore, an improvement in hepatomegaly associated with steatohepatitis is noted, if there is significant weight loss $(>3 \mathrm{~kg}$ fat loss in 2 weeks) [42]. VLCDs are dietary preparations that provide all nutritional requirements together with between 1850 and $3250 \mathrm{KJ}$ ( 450 and $800 \mathrm{Kcal}$ ) per day. An individual takes this meal replacement three times daily as a substitute for breakfast, lunch and dinner [43]. Obese people typically achieve a mean weight loss of $1.5-2.5 \mathrm{~kg}$ per week using a VLCD [44]. A 2001 meta-analysis concluded that, after using a VLCD, subjects maintained a significantly greater weight loss at compared to hypocaloric balanced diet $[45,46]$. The added benefit is that these special diets may also help with several obesity-related comorbidities by reducing levels of total cholesterol, low-density lipoprotein, triglycerides and blood glucose and by reducing blood pressure [44], insulin resistance [46], and hepatic steatosis [47].

All patients should undergo an appropriate nutritional evaluation, including selective micronutrient measurements [48], enabling correction of any deficiencies and optimization prior to the operation.

\section{Perioperative Considerations}

Most bariatric patients will have a difficult airway because of the neck circumference. However, if the patient is positioned appropriately during the anaesthetic, the incidence of difficult intubations is not higher than in the general population. Simple considerations, such as the transfer and positioning of the bariatric patient, become more complicated in the morbidly obese patient. Patient positioning is paramount. Sufficient manpower must be available to help transfer the anaesthetized patient from a bed to the operating table, and special inflation mattresses have been designed for this purpose. In a review of 155 patient safety incidents involving bariatric patients, 27 involved injury to staff as a direct result of difficulties with moving and handling [49]. Pressure points must be carefully padded, as any resulting pressure sores in patients who are at high risk of poor tissue healing can be troublesome [50].

Bariatric procedures are usually performed laparoscopically unless there is a contraindication such as previous extensive abdominal surgery. Therefore, patients are usually placed in a steep reverse Trendelenburg position, so care must be taken to ensure that patients are adequately restrained and are not likely to slip or fall off the table during surgery. Although offering a slight respiratory advantage [51, 52], this position, however, exacerbates venous pooling in the limbs, decreasing venous return and contributing to the high risk of venous thromboembolism. Using lower extremity compression devices, both during and after surgery, can decrease this risk. Often, morbidly obese patient's legs are too large for standard theatre compression stockings, so special foot pumps can be used. These devices can remain in place while the patient is in stationary during the postoperative period [53].

During the course of laparoscopic surgery, carbon dioxide must be insufflated into the abdomen. In nonobese patients, this is usually a pressure of $12 \mathrm{mmHg}$; however, this pressure is rarely sufficient to create enough space to perform bariatric surgery. Pressures of up to $15 \mathrm{mmHg}$ are routine during surgery [54], occasionally up to $20 \mathrm{mmHg}$.

The high pressures required to insufflate the abdomen during laparoscopic bariatric surgery can cause significant operative concerns to both the surgeon and the anaesthetist. The anaesthetic itself severely affects respiratory function, making adequate pulmonary ventilation and oxygenation difficult by decreasing the functional residual capacity [55]. The functional residual capacity of patients has been shown to be closely related to BMI. Increased pressures within the abdomen cause splinting of the diaphragm, further exacerbating this effect. The use of continuous positive airway pressure (CPAP) preoperatively can maintain oxygenation of patient's and control apnoeic episodes as well as aiding anaesthetic management of a difficult airway.

Complications can arise during routine laparoscopic surgery, such as bowel injury during trocar insertion, and pneumothorax. Given the higher pressures used during bariatric surgery and the decreased reserves of the bariatric patient, the anaesthetist and surgeon must have a high index of suspicion for events such as extraperitoneal insufflation, gas embolism, and surgical emphysema as these may exacerbate the strain already placed on the patient [51].

3.1. Postoperatively. In the immediate postoperative setting, most patients are managed at a high dependency unit, especially if they have a history of asthma or obstructive sleep apnoea. Some institutions use the Montefiore Obesity Surgery Score (MOSS) to help decide on which patients need IUT/HDU. These criteria include patients after gastric bypass, those with a BMI of $>50 \mathrm{~kg} / \mathrm{m}^{2}$, male sex, previous abdominal surgery, and significant comorbidity including sleep apnoea [55].

Most patients are provided with a PCA (patientcontrolled analgesia) device, which allows them to stay in control of their pain. This helps with ambulation and breathing exercises, both of which are important to avoid thrombosis and respiratory problems such as atelectasis or infection. The analgesic ladder should still be adhered to, as simple measures such as paracetamol can provide a good background pain relief.

There must be a high index of suspicion of thrombotic events for any patient that complains of breathlessness, pleuritic chest pain, swelling of the limbs, or haemoptysis. Given the prothrombotic nature of obesity and the difficulty mobilizing postoperatively, the risk of thrombosis is increased. In our centre, all patients, unless contraindicated 
are given thromboprophylaxis for 10 days after discharge from the hospital in order to reduce this risk. Pulmonary embolism (PE) is the most common cause of postoperative mortality, quotes around $1-2 \%[56,57]$. PE can be difficult to diagnose in the postoperative bariatric surgery: patients often present with profound hypoxia and hypotension, making it difficult to distinguish a PE from a postoperative leak.

Postoperative anastomotic leaks are also quoted at approximately $1-2 \%[56,57]$. This may be due to technical failure, or occasionally a staple line bleed causing a haematoma, which can cause the anastomosis to fail. Patients may mount signs of sepsis, although abdominal pain can be absent if analgesia is adequate. Given to poor tissue healing of bariatric patients due to inflammatory processes and poor nutritional states, these patients may be at a higher risk of anastomotic leak than nonobese patients. Again, there should be a high index of suspicion for leak. Many surgeons perform a leak test by injecting methylene blue dye down the nasogastric tube, although this may not determine which anastomoses are likely to fail postoperatively.

Bariatric surgery candidates are at risk for numerous vitamin and mineral deficiencies in the postoperative period due to altered eating patterns and malabsorptive consequences of the operation [29, 39, 58-65]. Postoperative nutritional deficiencies can depend on the type of surgery performed with fewer deficiencies with restrictive procedures (such as adjustable gastric banding and vertical banded gastroplasty, which is no longer routinely performed in the UK) as the entire gastrointestinal tract is retained [58].

In contrast, patients after gastric bypass are prone to deficiencies of the fat-soluble vitamins (A, D, E, and K) and calcium as well as an increased risk of developing anaemia secondary to deficiencies of iron, vitamin B12, and folate necessitating the indefinite supplementation of daily multivitamins $[59,60]$.

The partitioning of the stomach during bariatric surgery results in a dramatic decrease in the production of hydrochloric acid, affecting the absorption of calcium and iron [61]. Malabsorption of calcium and vitamin D occurs from bypassing these segments of intestine during bariatric operations. The malabsorption of vitamin $\mathrm{D}$ contributes further to calcium malabsorption. With a relative lack of calcium, the production of parathyroid hormone $(\mathrm{PTH})$ is increased, which leads to the release of calcium from bone, potentially causing bone loss and long-term risk of osteoporosis [29]. For this reason, early bone densitometry testing, although not routine, would be sensible [61].

The duodenum is the primary site for absorption of iron and may be bypassed. Ferric iron consumed in the diet can be absorbed as ferrous by the use of ascorbic acid supplementation, which aid the acidic environment for conversion of iron [37, 63, 64]. Monthly vitamin B12 injections supplement levels of a vitamin whose absorption may be impaired due to decreased intrinsic factor, which is produced in the parietal cells of the stomach $[39,64]$.

Deficiencies of thiamine occur frequently in patients with good weight loss postoperatively. Thiamine stores are limited, is absorbed in the proximal small intestine and may become deficient after a combination of reduced intake, frequent vomiting, and malabsorption [29]. This may cause Wernicke's disease with irreversible neuropathy or death. Supplementation of a minimum of $10 \mathrm{mg}$ thiamine during periods of rapid weight loss can prevent these serious consequences [39, 65].

Average inpatient stay in the UK according to the National Bariatric Service registry is 3 days. After that patients are discharged, but continue under the care of the bariatric services as an outpatient. Patient followup varies between units and surgeons. Currently in our unit, patients are followed up after bariatric surgery for 2 years. After this, if the patients have no complications, their followup is referred back to primary care. Patients who experience complications from their surgery often continue with followup as deemed appropriate by their surgeon.

\section{Conclusion}

Bariatric surgery is fraught with complexities that need careful consideration. All members of the multidisciplinary team must be involved throughout all stages of assessment, surgery, and followup. Weight loss surgery is associated with a decrease in obesity related co-morbidities, which often are not seen in lifestyle changes alone. Patients must be fully counselled on the operative and postoperative sequelae of surgery so that they understand the risks. Ensuring that patients are fully optimized before their surgery and receive the appropriate levels of care during and after their operations is paramount.

\section{References}

[1] http://www.dh.gov.uk/en/Publichealth/Obesity/DH_078098.

[2] M. H. Davidson, J. Hauptman, M. DiGirolamo et al., "Weight control and risk factor reduction in obese subjects treated for 2 years with orlistat: a randomized controlled trial," JAMA, vol. 281, no. 3, pp. 235-242, 1999.

[3] R. S. Padwal and S. R. Majumdar, "Drug treatments for obesity: orlistat, sibutramine, and rimonabant," The Lancet, vol. 369, no. 9555, pp. 71-77, 2007.

[4] A. Sabharwal and N. Christelis, "Anaesthesia for bariatric surgery," Continuing Education in Anaesthesia, Critical Care \& Pain, vol. 10, no. 4, pp. 99-103, 2010.

[5] C. Ni Mhurchu, A. Rodgers, W. H. Pan et al., "Body mass index and cardiovascular disease in the Asia-Pacific region: an overview of 33 cohorts involving 310,000 participants," International Journal of Epidemiology, vol. 33, pp. 751-758, 2004.

[6] P. R. Schauer, B. Burguera, S. Ikramuddin et al., "Effect of laparoscopic Roux-en Y gastric bypass on type 2 diabetes mellitus," Annals of Surgery, vol. 238, no. 4, pp. 467-485, 2003.

[7] S. Kenchaiah, J. C. Evans, D. Levy et al., "Obesity and the risk of heart failure," The New England Journal of Medicine, vol. 347, pp. 305-313, 2002.

[8] L. Frost, L. J. Hune, and P. Vestergaard, "Overweight and obesity as risk factors for atrial fibrillation or flutter: the Danish Diet, Cancer, and Health Study," American Journal of Medicine, vol. 118, no. 5, pp. 489-495, 2005.

[9] T. J. Wang, H. Parise, D. Levy et al., "Obesity and the risk of new-onset atrial fibrillation,” JAMA, vol. 292, pp. 2471-2477, 2004. 
[10] W. Ageno, C. Becattini, T. Brighton, R. Selby, and P. W. Kamphuisen, "Cardiovascular risk factors and venous thromboembolism: a meta-analysis," Circulation, vol. 117, no. 1, pp. 93-102, 2008.

[11] National Institutes of Health, "Clinical guidelines on the identification, evaluation, and treatment of overweight and obesity in adults-the evidence report," Obesity Research, vol. 6, supplement 2, pp. 51S-209S, 1998.

[12] F. X. Pi-Sunyer, "A review of long-term studies evaluating the efficacy of weight loss in ameliorating disorders associated with obesity," Clinical Therapeutics, vol. 18, no. 6, pp. 1006$1035,1996$.

[13] D. B Allison and F. X. Pi-Sunyer, "Obesity treatment: examining the premises," Endocrine Practice, vol. 1, pp. 353-364, 1995.

[14] T. Young, J. Skatrud, and P. E. Peppard, "Risk factors for obstructive sleep apnea in adults," JAMA, vol. 291, no. 16, pp. 2013-2016, 2004.

[15] E. J. DeMaria, "Bariatric surgery for morbid obesity," The New England Journal of Medicine, vol. 356, no. 21, pp. 2176-2183, 2007.

[16] National Institutes of Health Consensus Development Panel, "Gastrointestinal surgery for severe obesity," Obesity Surgery, vol. 1, pp. 257-265, 1991.

[17] H. Buchwald, Y. Avidor, E. Braunwald et al., "Bariatric surgery: a systematic review and meta-analysis," JAMA, vol. 292, no. 14, pp. 1724-1737, 2004.

[18] D. J. Goldstein, "Beneficial health effects of modest weight loss," International Journal of Obesity, vol. 16, no. 6, pp. 397415, 1992.

[19] W. C. Knowler, E. Barrett-Connor, S. E. Fowler et al., "Reduction in the incidence of type 2 diabetes with lifestyle intervention or metformin," The New England Journal of Medicine, vol. 346, no. 6, pp. 393-403, 2002.

[20] G. Mingrone and M. Castagneto, "Bariatric surgery: unstressing or boosting the $\beta$-cell?” Diabetes, Obesity and Metabolism, vol. 11, supplement 4, pp. 130-142, 2009.

[21] J. C. Lifante and W. B. Inabnet, "Early improvement in type 2 diabetes in obese patients following gastric bypass and bilio-pancreatic diversion: the role of the entero-insular axis," Journal de Chirurgie, vol. 145, no. 6, pp. 549-555, 2008.

[22] S. A. Cunneen, "Review of meta-analytic comparisons of bariatric surgery with a focus on laparoscopic adjustable gastric banding," Surgery for Obesity and Related Diseases, vol. 4, no. 3, supplement, pp. S47-S55, 2008.

[23] R. S. Gill, D. W. Birch, X. Shi, A. M. Sharma, and S. Karmali, "Sleeve gastrectomy and type 2 diabetes mellitus: a systematic review," Surgery for Obesity and Related Diseases, vol. 6, no. 6, pp. 707-713, 2010.

[24] G. Nosso, L. Angrisani, G. Saldalamacchia et al., "Impact of sleeve gastrectomy on weight loss, glucose homeostasis, and comorbidities in severely obese type 2 diabetic subjects," Journal of Obesity, vol. 2011, Article ID 340867, 4 pages, 2011.

[25] J. L. Colquitt, J. Picot, E. Loveman, and A. J. Clegg, "Surgery for obesity," Cochrane Database of Systematic Reviews, no. 2, Article ID CD003641, 2009.

[26] E. H. Livingston, "Complications of bariatric surgery," Surgical Clinics of North America, vol. 85, no. 4, pp. 853-868, 2005.

[27] P. D. Stein, A. Beemath, and R. E. Olson, "Obesity as a risk factor in venous thromboembolism," American Journal of Medicine, vol. 118, no. 9, pp. 978-980, 2005.

[28] K. Clément, N. Viguerie, C. Poitou et al., "Weight loss regulates inflammation-related genes in white adipose tissue of obese subjects," The FASEB Journal, vol. 18, no. 14, pp. 1657-1669, 2004.
[29] H. P. Kopp, C. W. Kopp, A. Festa et al., "Impact of weight loss on inflammatory proteins and their association with the insulin resistance syndrome in morbidly obese patients," Arteriosclerosis, Thrombosis, and Vascular Biology, vol. 23, no. 6, pp. 1042-1047, 2003.

[30] C. E. Yale, "Gastric surgery for morbid obesity. Complications and long-term weight control," Archives of Surgery, vol. 124, no. 8, pp. 941-946, 1989.

[31] R. E. Brolin, "Complications of surgery for severe obesity," Problems in General Surgery, vol. 17, no. 2, pp. 55-61, 2000.

[32] H. Buchwald, R. Estok, K. Fahrbach et al., "Weight and type 2 diabetes after bariatric surgery: systematic review and metaanalysis," American Journal of Medicine, vol. 122, no. 3, pp. 248-256.e5, 2009.

[33] M. W. Hinojosa, J. E. Varela, B. R. Smith, F. Che, and N. T. Nguyen, "Resolution of systemic hypertension after laparoscopic gastric bypass," Journal of Gastrointestinal Surgery, vol. 13, no. 4, pp. 793-797, 2009.

[34] J. E. Varela, M. Hinojosa, and N. Nguyen, "Correlations between intra-abdominal pressure and obesity-related comorbidities," Surgery for Obesity and Related Diseases, vol. 5, no. 5, pp. 524-528, 2009.

[35] M. Ruano, V. Silvestre, Y. Domínguez et al., "Morbid obesity, hypertensive disease and the renin-angiotensin-aldosterone axis," Obesity Surgery, vol. 15, no. 5, pp. 670-676, 2005.

[36] M. Lakhani and S. Fein, "Effects of obesity and subsequent weight reduction on left ventricular function," Cardiology in Review, vol. 19, no. 1, pp. 1-4, 2011.

[37] A. E. Sareli, C. R. Cantor, N. N. Williams et al., "Obstructive sleep apnea in patients undergoing bariatric surgery-a tertiary center experience," Obesity Surgery, vol. 21, no. 3, pp. 316-327, 2011.

[38] P. W. Olejniczak and B. J. Fisch, "Sleep disorders," Medical Clinics of North America, vol. 87, no. 4, pp. 803-833, 2003.

[39] J. I. Alvarez-Leite, "Nutrient deficiencies secondary to bariatric surgery," Current Opinion in Clinical Nutrition \& Metabolic Care, vol. 7, pp. 569-575, 2004.

[40] C. Schweiger, R. Weiss, E. Berry, and A. Keidar, "Nutritional deficiencies in bariatric surgery candidates," Obesity Surgery, vol. 20, no. 2, pp. 193-197, 2010.

[41] L. Flancbaum, S. Belsley, V. Drake, T. Colarusso, and E. Tayler, "Preoperative nutritional status of patients undergoing roux-en-Y gastric bypass for morbid obesity," Journal of Gastrointestinal Surgery, vol. 10, no. 7, pp. 1033-1037, 2006.

[42] R. J. Fris, "Preoperative low energy diet diminishes liver size," Obesity Surgery, vol. 14, no. 9, pp. 1165-1170, 2004.

[43] E. Delbridge and J. Proietto, "State of the science: VLED (Very Low Energy Diet) for obesity," Asia Pacific Journal of Clinical Nutrition, vol. 15, supplement, pp. 49-54, 2006.

[44] P. Sumithran and J. Proietto, "Safe year-long use of a verylow-calorie diet for the treatment of severe obesity," Medical Journal of Australia, vol. 188, no. 6, pp. 366-368, 2008.

[45] J. W. Anderson, E. C. Konz, R. C. Frederich, and C. L. Wood, "Long-term weight-loss maintenance: a meta-analysis of US studies," American Journal of Clinical Nutrition, vol. 74, no. 5, pp. 579-584, 2001.

[46] P. Mustajoki and T. Pekkarinen, "Very low energy diets in the treatment of obesity," Obesity Reviews, vol. 2, no. 1, pp. 61-72, 2001.

[47] M. C. Lewis, M. L. Phillips, J. P. Slavotinek, L. Kow, C. H. Thompson, and J. Toouli, "Change in liver size and fat content after treatment with Optifast ${ }^{\circledR}$ very low calorie diet," Obesity Surgery, vol. 16, no. 6, pp. 697-701, 2006. 
[48] J. I. Mechanick, R. F. Kushner, H. J. Sugerman et al., "American Association of Clinical Endocrinologists, The Obesity Society, and American Society for Metabolic \& Bariatric Surgery Medical Guidelines for Clinical Practice for the Perioperative Nutritional, Metabolic, and Nonsurgical Support of the Bariatric Surgery Patient," Surgery for Obesity and Related Diseases, vol. 4, no. 5, pp. S109-S184, 2008.

[49] C. M. A. Booth, C. E. Moore, J. Eddleston, M. Sharman, D. Atkinson, and J. A. Moore, "Patient safety incidents associated with obesity: a review of reports to the National Patient Safety Agency and recommendations for hospital practice," Postgraduate Medical Journal, vol. 87, pp. 694-699, 2011.

[50] J. B. Brodsky, "Positioning the morbidly obese patient for anesthesia," Obesity Surgery, vol. 12, no. 6, pp. 751-758, 2002.

[51] A. J. Cunningham, "Anesthetic implications of laparoscopic surgery," Yale Journal of Biology and Medicine, vol. 71, no. 6, pp. 551-578, 1999.

[52] V. Perilli, L. Sollazzi, P. Bozza et al., "The effects of the reverse trendelenburg position on respiratory mechanics and blood gases in morbidly obese patients during bariatric surgery," Anesthesia and Analgesia, vol. 91, no. 6, pp. 1520-1525, 2000.

[53] S. A. Cotter, W. Cantrell, B. Fisher, and R. Shopnick, "Efficacy of venous thromboembolism prophylaxis in morbidly obese patients undergoing gastric bypass surgery," Obesity Surgery, vol. 15, no. 9, pp. 1316-1320, 2005.

[54] M. Daskalakis, O. Scheffel, and R. A. Weiner, "High flow insufflation for the maintenance of the pneumoperitoneum during bariatric surgery," Obesity Facts, vol. 2, supplement 1, pp. 37-40, 2009.

[55] A. Sabharwal, "N ChristelisAnaesthesia for bariatric surgery," Continuing Education in Anaesthesia, Critical Care \& Pain, vol. 10, no. 4, pp. 99-103, 2010.

[56] http://www.danaise.com/bariatric.htm.

[57] B. M. Rhode, C. Shustik, N. V. Christou, and L. D. MacLean, "Iron absorption and therapy after gastric bypass," Obesity Surgery, vol. 9, no. 1, pp. 17-21, 1999.

[58] A. D. Miller and K. M. Smith, "Medication and nutrient administration considerations after bariatric surgery," American Journal of Health-System Pharmacy, vol. 63, no. 19, pp. 1852-1857, 2006.

[59] R. E. Brolin, "Metabolic deficiencies and supplements following bariatric operations," in Obesity Surgery, L. F. Martin, Ed., pp. 275-299, McGraw-Hill, New York, NY, USA, 1st edition, 2004.

[60] T. A. Ponsky, F. Brody, and E. Pucci, "Alterations in gastrointestinal physiology after Roux-en-Y gastric bypass," Journal of the American College of Surgeons, vol. 201, no. 1, pp. 125-131, 2005.

[61] B. E. C. Nordin, P. D. O'Loughlin, A. G. Need, M. Horowitz, and H. A. Morris, "Radiocalcium absorption is reduced in postmenopausal women with vertebral and most types of peripheral fractures," Osteoporosis International, vol. 15, no. 1, pp. 27-31, 2004.

[62] E. Harju, "Clinical pharmacokinetics of iron preparations," Clinical Pharmacokinetics, vol. 17, no. 2, pp. 69-89, 1989.

[63] K. E. Behrns, C. D. Smith, and M. G. Sarr, "Prospective evaluation of gastric acid secretion and cobalamin absorption following gastric bypass for clinically severe obesity," Digestive Diseases and Sciences, vol. 39, no. 2, pp. 315-320, 1994.

[64] L. D. MacLean, B. M. Rhode, and H. M. Shizgal, "Nutrition following gastric operations for morbid obesity," Annals of Surgery, vol. 198, no. 3, pp. 347-355, 1983.
[65] R. D. Bloomberg, A. Fleishman, J. E. Nalle, D. M. Herron, and S. Kini, "Nutritional deficiencies following bariatric surgery: what have we learned?" Obesity Surgery, vol. 15, no. 2, pp. 145154, 2005. 


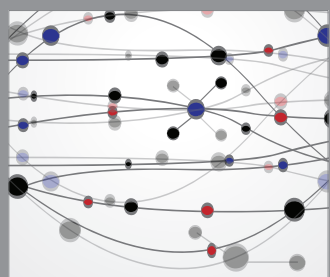

The Scientific World Journal
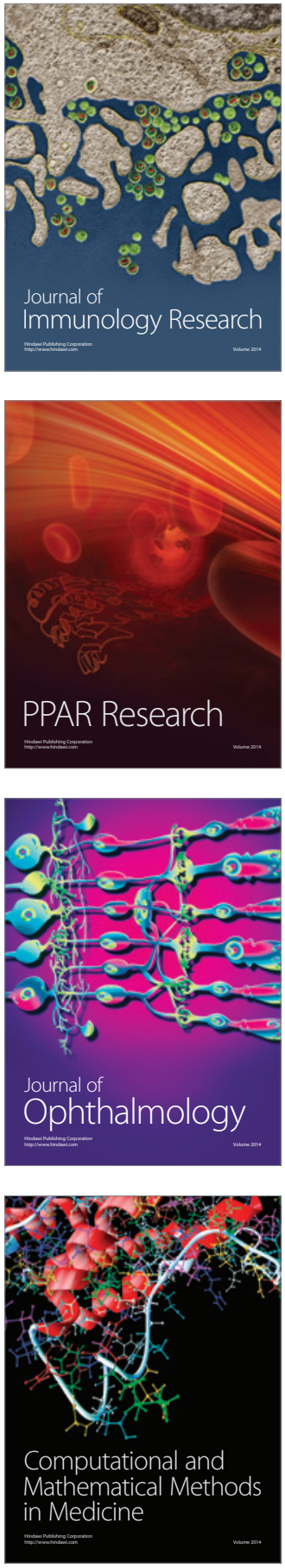

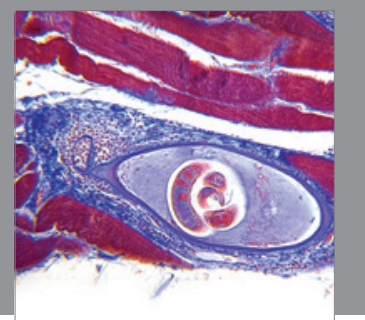

Gastroenterology

Research and Practice
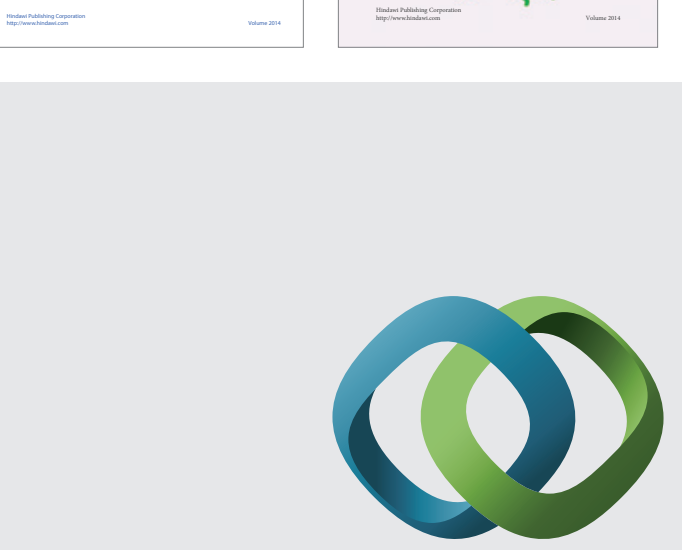

\section{Hindawi}

Submit your manuscripts at

http://www.hindawi.com
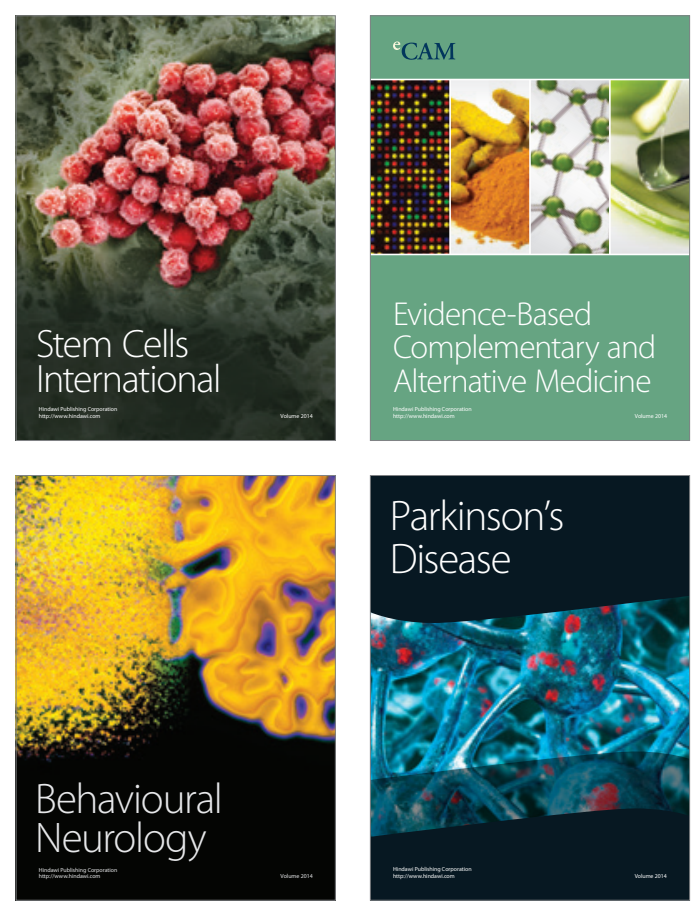

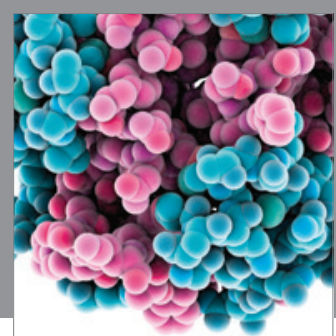

Journal of
Diabetes Research

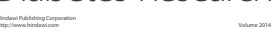

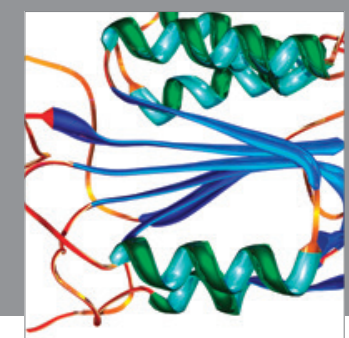

Disease Markers
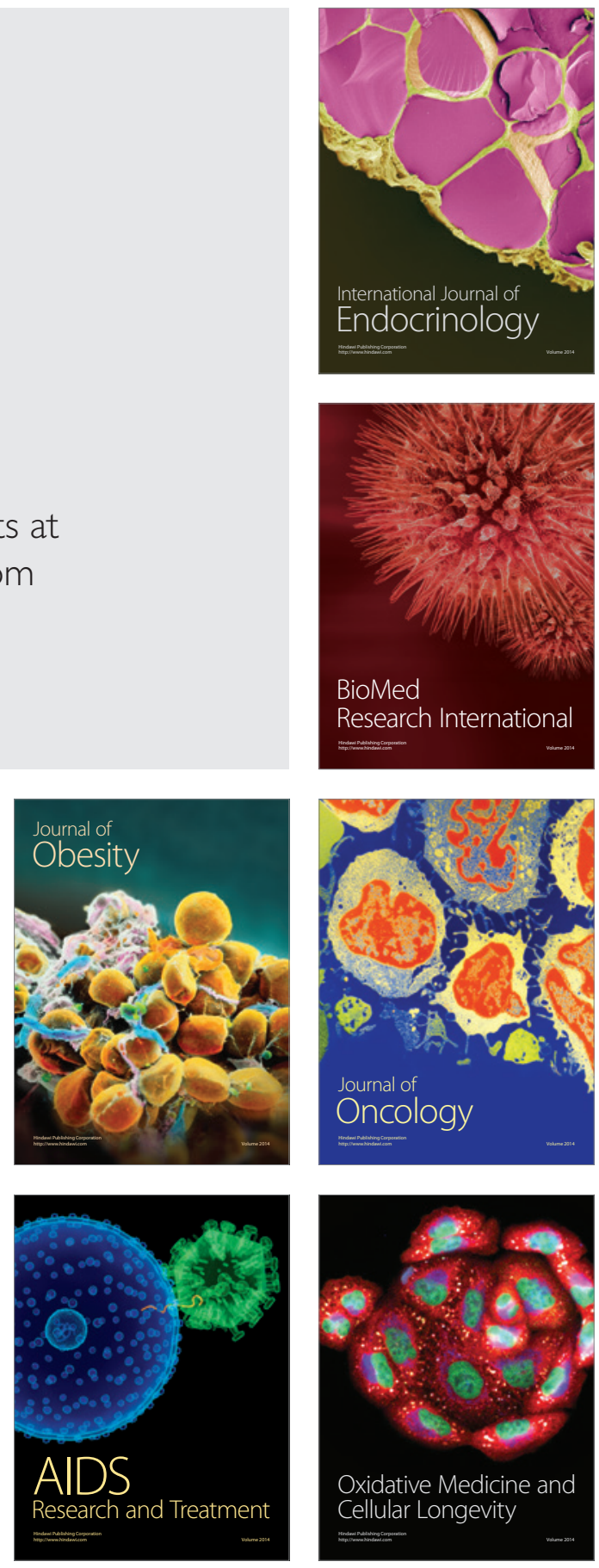